\title{
LAS RELACIONES ENTRE LA JUSTICIA CONSTITUCIONAL Y EL LEGISLADOR EN EUROPA
}

\author{
JOSÉ MARÍA PORRAS RAMÍREZ
}

RESUMO: O artigo discute as transformações operadas na forma de realização do controle de constitucionalidade nas jurisdições européias. Analisa-se principalmente a transição de uma tradição de controle constitucional meramente negativo (Estado Liberal) para um novo modelo de controle também positivo (Estado Social), o controle hermenêutico (da interpretação das normas) e o controle determinador de produção legislativa. São mostrados alguns problemas do novo modelo e sugeridas soluções como a maior integração entre a atuação do Tribunal Constitucional e do Poder Legislativo em cada país europeu.

PALAVRAS-CHAVE: Controle de Constitucionalidade. Poder Legislativo. Interpretação Constitucional. Europa.

ABSTRACT: The article discusses the transformations in the way constitutional review is performed in European jurisdictions. It analyzes mainly the transition from a merely negative constitutional review tradition (Liberal State) to a new model of review that is also positive (Social State), the hermeneutical review (of statutory interpretation) and the constitutional review assertive of the need to produce legislation. Some problems of the new model are shown and solutions are suggested, such as a higher integration between the Constitutional Court's action and that of the Legislative Power in each European country. KEYWORDS: Constitutional Review. Legislative Power. Constitutional Interpretation. Europe.

SUMÁRIO: 1. Traços característicos do modelo Europeu de Justiça Constitucional; 2. A transição a uma nova forma de relação entre a Justiça Constitucional e o legislador; 3. As transformações experimentadas; 3.1. A consolidação do Estado Social e Democrático de Direito; 3.2. As mudanças no desenvolvimento dos procedimentos de controle constitucional das leis; 3.2.1. O objeto do controle de constitucionalidade; 3.2.2. O cânone de constitucionalidade; 3.2.3. O conteúdo das sentenças constitucionais e seus diferentes tipos; 3.2.4. Os efeitos das sentenças constitucionais; Conclusões; Referências.

SUMMARY: 1. Characteristic traits of the European model of Constitutional Justice; 2. The transition to a new form of relationship between the Constitutional Justice and the legislator; 3. The transformations undergone; 3.1. The consolidation of the Social and Democratic State of Law; 3.2. The changes in the development of mechanisms of constitutional review of statutes; 3.2.1. The object of constitutional review; 3.2.2. The constitutionality canon; 3.2.3. The content of constitutional review decisions and their different types; 3.2.4. The effects of constitutional review decisions; Conclusions; References.

Artigo recebido em 17.05.2010 - Elaboração dos Pareceres em 24.06.2010.

Aprovado para publicação pelo Conselho Editorial em 07.07.2010.

* Catedrático de Direito Constitucional da Universidade de Granada, Espanha. 
SUMARIO: 1. Rasgos característicos del modelo europeo de Justicia Constitucional; 2. La transición a una nueva forma de relación entre la Justicia Constitucional y el legislador; 3. Transformaciones experimentadas; 3.1. La consolidación del Estado social y democrático de derecho; 3.2. Los cambios en el desarrollo de los procedimientos de control de constitucionalidad de las leyes; 3.2.1. El objeto del control de constitucionalidad; 3.2.2. El canon de constitucionalidad; 3.2.3. El contenido de las sentencias constitucionales y sus diferentes tipos; 3.2.4. Los efectos de las sentencias; Conclusiones; Referencias.

\section{RASGOS CARACTERÍSTICOS DEL MODELO EUROPEO DE JUSTICIA CONSTITUCIONAL}

En Europa continental, de acuerdo con la concepción jurídico-política inspirada por el liberalismo, existió, a raíz de la implantación del Estado legal de Derecho, una fuerte resistencia a la creación de un sistema judicial de revisión de las leyes, similar al creado, a partir de 1803, en los Estados Unidos de América. Predominó así, hasta bien entrado el siglo XX, la idea de que ningún órgano judicial podía imponerse a las decisiones adoptadas por el Parlamento, en tanto que encarnación legítima de la soberanía nacional, ya que ello conculcaba el principio fundamental de la división de poderes, rígidamente interpretado ${ }^{1}$.

No obstante, la necesidad de garantizar el valor normativo y supremo de la Constitución motivó que, con el tiempo, se gestara un sistema de justicia constitucional concentrada, expresado por medio de un Tribunal Constitucional. Dicho órgano restringía sus actuaciones a la anulación de aquellas leyes que resultaban contrarias a la Norma Fundamental ${ }^{2}$. Así, dicho Tribunal fue concebido, esencialmente, como una suerte de legislador negativo ${ }^{3}$. Esta función atribuida al mismo ha informado, de manera constante, su actuación más destacada. A ella, que le permite actuar como Tribunal de la ley, se han sumado con el tiempo, aunque no siempre, según en qué Estados, atribuciones que lo facultan para actuar, igualmente, como Tribunal de conflictos, resolviendo los que se generan entre las altas instituciones del Estado, $\mathrm{y}$ entre la federación y los territorios, esencialmente; y, también, como Tribunal de la libertad, amparando extraordinariamente los derechos fundamentales de las personas.

Centrándonos en esa concepción primigenia del legislador negativo, hay que insistir en que la misma, tal y como fue formulada originariamente por $\mathrm{H}$. Kelsen, sigue siendo, sin duda, el eje central de las regulaciones que las Constituciones europeas dedican a los respectivos Tribunales Constitucionales. Y precisamente es aquélla que se esgrime cada vez que una sentencia ha de contradecir claramente lo dispuesto por la mayoría representada en el Parlamento. Así, de acuerdo con esta teoría, que implica un reparto estricto o rígido de funciones, es la Asamblea quien ha de elaborar las leyes, y el Tribunal Constitucional quien ha de limitarse a anular los preceptos legales impugnados que determina contrarios a la Constitución.

\footnotetext{
${ }^{1}$ E. García de Enterría, “La Constitución como norma y el Tribunal Constitucional”, Madrid, Civitas, 1981, págs. 123 y ss.

${ }^{2}$ Cfr., por todos, P. Cruz Villalón, "La formación del Sistema Europeo de Control de Constitucionalidad 1918-1939”, Madrid, Centro de Estudios Constitucionales, 1987, pássim.

${ }^{3}$ H. Kelsen, "La garantie jurisdictionnelle de la Constititution (La Justice constitutionnelle)", en Revue de Droit Public, Vol. XLV, 1928, págs. 197 y ss.
} 
No obstante, a nadie se le oculta que ese cometido eminentemente negativo conlleva una modificación del ordenamiento que puede tener, también, consecuencias positivas. No en vano, las sentencias constitucionales concretizan la Constitución, mediante su interpretación, formulando normas subconstitucionales que integran y ayudan a comprender a aquéllas que conforman su texto normativo explícito ${ }^{4}$.

\section{LA TRANSICIÓN A UNA NUEVA FORMA DE RELACIÓN ENTRE}

\section{LA JUSTICIA CONSTITUCIONAL Y EL LEGISLADOR}

Es así que hace ya mucho tiempo que, de acuerdo con la práctica observada, los Tribunales Constitucionales europeos han abandonado esa rigurosa visión kelseniana del legislador negativo, al asumir decididamente una labor positiva, de creación de normas. Sin embargo, paradójicamente, ello no ha supuesto una revisión completa de la teoría clásica indicada, al seguir considerándose, cuando menos oficialmente, que las sentencias positivas responden, excepcionalmente, a casos especiales, demandantes de una intervención extraordinaria, por parte del órgano jurisdiccional de referencia, orientada a la sustitución inmediata de los preceptos que él mismo anuló.

En cualquier caso, la explicación de la pervivencia de esa idea original, que ya no responde a la realidad, como justificación general de la existencia de una Justicia Constitucional en los diferentes Estados de Europa, se debe no sólo a su simplicidad, lo que dificulta su reemplazo, sino a su perfecta adecuación a los esquemas del Estado legal de Derecho decimonónico, aun culturalmente dominantes en la mentalidad iuspublicista europea, que postula un particular entendimiento de la división de poderes, fundado en la existencia de un Parlamento omnipotente, y de una justicia subordinada, que aplica la ley, anulándola en las contadas ocasiones en que contradice palmariamente la Constitución.

No obstante, la continuidad de ese modelo resulta muy perjudicial, ya que explica inadecuadamente la realidad presente, habida cuenta de su anacronismo y obsolescencia. Ello otorga, en la práctica, carta blanca a los Tribunales Constitucionales para que, ante la ausencia de previsiones expresas facultándolos para dictar sentencias positivas, elaboren una gran variedad de resoluciones, muchas de ellas no contempladas por sus respectivas leyes reguladoras, que hagan cuestionar su legitimidad. Así, en Europa, ante esa habitual falta de fundamento legal, cuando los Tribunales Constitucionales crean normas nuevas, suele justificarse afirmando que los mismos no sólo actúan como defensores de la Constitución, sino, también, como defensores de la ley, por lo que tienden, a no anularla, sino a conservarla, recreándola, cambiando su sentido. Se impone así una renovación de la teoría de la división de poderes que profundice en la consideración del Tribunal Constitucional como órgano constitucional, contemplando una colaboración más estrecha entre el legislador y la justicia constitucional, que incluya mecanismos formales de relación ${ }^{5}$.

De todas formas, lo cierto es que, en su realidad cotidiana, los Tribunales Constitucionales han asumido, en Europa, una tan significativa como ordinaria función

\footnotetext{
${ }^{4}$ M. Cappelletti, "Il controllo giudiziario di costituzionalità delle leggi nel Diritto comparato”, Milano, Giuffré, 1979, págs. 61 y ss.

${ }^{5}$ Así, vid., a este respecto, el espléndido libro coordinado por E. Aja Fernández (ed.), "Las tensiones entre el Tribunal Constitucional y el Legislador en la Europa actual”, Barcelona, Ariel, 1998.
} 
de legisladores positivos, adoptando un tipo de sentencias, conocidas con diferentes denominaciones, según los diversos países: interpretativas, aditivas, manipulativas, sustitutivas, constructivas, apelativas, etc., mediante las cuales no se limitan a suprimir el precepto legal impugnado que se considera contrario a la Constitución, sino, al tiempo, a incorporar una norma nueva al ordenamiento. Se trata de un fenómeno relativamente nuevo y de intensidad creciente, que ha de valorarse en su justa importancia ${ }^{6}$.

\section{TRANSFORMACIONES EXPERIMENTADAS}

Este hecho se ha explicado atendiendo, tanto a la calificación constitucional del Estado como social y democrático de Derecho; como a razones estructurales que afectan al funcionamiento específico de la propia Justicia Constitucional.

\subsection{La consolidación del Estado social y democrático de derecho}

Así, en primer lugar, es un hecho cierto que la consolidación del Estado social y democrático de Derecho ha afectado a la Justicia Constitucional notablemente. Ello se refleja, en primer lugar, en el incremento cuantitativo, verdaderamente formidable, de la legislación, en el contexto del intervencionismo constante de los poderes públicos en todos los ámbitos de la realidad social, lo que ha supuesto una multiplicación de las sentencias de los Tribunales Constitucionales, los cuales, de esa forma, han visto incrementado, de manera sustancial, su protagonismo en el funcionamiento del sistema político. A ello se une, la consideración de los derechos y libertades de los ciudadanos como fundamento mismo del ordenamiento jurídico-político, lo que obliga a los Tribunales Constitucionales a efectuar un examen mucho más riguroso y exhaustivo de la legislación que afecta a aquéllos. Ambos factores, unidos, al papel que en algunos Estados desempeña el correspondiente Tribunal Constitucional, velando por el adecuado reparto de competencias entre la Federación y los territorios, han repercutido en su posición y funciones, suponiendo la asunción de tareas nuevas. A lo indicado se añade la ampliación de los sujetos capacitados para impetrar la actuación de tan cualificado órgano jurisdiccional, hecho éste que ha supuesto una apreciable extensión y mejora de su legitimidad ${ }^{7}$.

En el marco de esa situación, considerablemente más compleja que aquella que se daba cuando nacieron los primeros Tribunales Constitucionales europeos, durante el período de entreguerras, la dicotomía validez-nulidad, consustancial a la teoría del legislador negativo, se vuelve, en parte, disfuncional, ya que su aplicación estricta generaría efectos perniciosos, habida cuenta de que, en ocasiones, anular una ley, produciendo el consiguiente vacío regulador, por ejemplo, en materia de impuestos o de pensiones, puede revelarse, en ocasiones, más lesivo y perjudicial que mantenerla en vigor, pese a su carácter contrario a la Constitución, a menos que el propio Tribunal adopte medidas para limitar o corregir las consecuencias de sus sentencias.

Por tanto, la actitud positiva de los Tribunales Constitucionales, lejos de ser un fenómeno aislado, ha comenzado a ser vista, en Europa, como la expresión de una

${ }^{6}$ F. Rubio Llorente, “La jurisdicción constitucional como forma de creación del Derecho”, en "La forma del poder”, Madrid, 1993, págs. 510 y ss.

${ }^{7}$ Así, J. Pérez Royo, “Tribunal Constitucional y división de poderes”, Madrid, Tecnos, 1988, págs. 24 y ss. 
actividad generalizada y habitual. Manifestación sobresaliente de la misma son las llamadas "sentencias intermedias", esto es, aquéllas que no sólo declaran la validez o la nulidad de la ley impugnada, sino que introducen, al tiempo, normas nuevas en el ordenamiento, implicando una actividad de legislación positiva.

\subsection{Los cambios en el desarrollo de los procedimientos de control de constitucionalidad de las leyes}

El otro condicionante a tener en cuenta, que propicia la ampliación de las funciones positivas de los Tribunales Constitucionales, tiene que ver con los factores estructurales que afectan al funcionamiento mismo de la Justicia Constitucional. Los mismos traen causa de las transformaciones operadas en la relación que se entabla, en Europa, entre el Tribunal Constitucional y el legislador en los procedimientos de control de constitucionalidad de las leyes.

Dichas transformaciones repercuten en la consideración que tradicionalmente ha merecido: 1) El objeto del control de constitucionalidad; 2) El canon o parámetro de constitucionalidad; 3) El contenido de las sentencias constitucionales y sus diferentes tipos; y 4) Los efectos de las sentencias constitucionales.

\subsubsection{El objeto del control de constitucionalidad}

A los efectos de esta exposición, hay que recordar que la mayoría de las normas reguladoras de los Tribunales Constitucionales europeos determinan que son objeto de control de constitucionalidad las leyes o normas con rango de ley. No obstante cabe distinguir entre el enunciado legal, esto es, entre el precepto de la ley, y las normas que alberga. Esta distinción está en la base de las sentencias intermedias, ya que una sentencia interpretativa permite conservar el precepto legal y, al tiempo, excluir una determinada interpretación de su contenido normativo ${ }^{8}$.

De esta forma, la mayoría de las sentencias interpretativas aparecen formalmente como desestimatorias del recurso de inconstitucionalidad, al mantener la vigencia del enunciado legal, pese a ser, en realidad, estimatorias de la demanda, ya que excluyen a una determinada norma que podría derivarse del precepto. Esa disociación precepto legal-norma se produce porque mientras que el objeto del recurso tiene una consideración formal, el objeto de enjuiciamiento y del pronunciamiento puede ser material, distinguiendo entre las normas que encierra el precepto y aceptando la inconstitucionalidad de unas pero no de otras.

Ese enfoque material se acentúa en las cuestiones de inconstitucionalidad planteadas por los jueces y los tribunales ordinarios, ya que, en tales casos, el Tribunal Constitucional analiza la ley en relación a su aplicación en un caso concreto, y puede así poner de relieve efectos materiales de la norma muy específicos, determinados por las circunstancias del caso. De este modo, en España, aunque el propio Tribunal Constitucional ha rechazado, respetando el principio de congruencia, que el "petitum” de la demanda solicite una sentencia interpretativa, lo cierto es que las ha dictado, con notable flexibilidad, distinguiendo entre el precepto legal y las normas que el mismo contiene ${ }^{9}$.

${ }^{8}$ F. Rubio Llorente, “La Jurisdicción Constitucional como forma de creación del Derecho”, op. cit., pág. 515.

${ }^{9}$ J. Jiménez Campo, "La declaración de inconstitucionalidad de la ley”, en F. Rubio Llorente y J. Jiménez Campo, “Estudios sobre Jurisdicción Constitucional”, Madrid, McGraw-Hill, 1998, págs. 130 y ss. 
No obstante, este hecho puede, también, generar problemas, como el del aislamiento de la norma inconstitucional en el precepto impugnado; o como el que provoca el mantenimiento formal de un precepto legal cambiando las normas que contiene. Esta alternativa tiene consecuencias en la extensión de los efectos de la sentencia, porque si se determina la nulidad del precepto, obviamente la disposición desaparece, pero si la sentencia es de conformidad con la Constitución, la misma norma contenida en una ley diferente puede volver a ser impugnada, tanto en el recurso como en la cuestión de inconstitucionalidad. De todas formas, los mayores problemas se plantean cuando la declaración de inconstitucionalidad no sólo deriva de la ley impugnada, sino de un sistema normativo que descansa también en otras leyes no impugnadas. Así, los Tribunales Constitucionales europeos suelen extender sus pronunciamientos a otros preceptos de la ley no impugnados, si guardan alguna relación con el objeto del recurso. De esa forma sucede, expresamente, en Alemania (art. 38 LTCFA) y en España “por conexión o consecuencia” (art. 39 LOTC), pero, en ambos casos, limitándose a las normas de la ley recurrida. En cambio, en Austria, sólo se acepta extender los efectos de la sentencia cuando la norma declarada inconstitucional vulnera la distribución de competencias y cuando se demuestra que la ley fue publicada de forma inconstitucional. En Italia, como excepción, se acepta la extensión del efecto de inconstitucionalidad cuando deriva de la declaración de la Corte (art. 27 LTCI). En la práctica, ello permite que la sentencia afecte a leyes diferentes de la recurrida. Esa extensión del objeto enjuiciado también se observa en Francia, donde es criticada la excesiva libertad del Tribunal Constitucional al respecto, ya que no se precisa la demostración de la conexión ${ }^{10}$.

\subsubsection{El canon de constitucionalidad}

En los procedimientos de control de constititucionalidad de las leyes, en virtud de su especial rango normativo supremo, la Constitución opera toda ella como canon de constitucionalidad. Es así que la misma permite al legislador efectuar un desarrollo diverso, según su orientación política. De ahí que el Tribunal Constitucional deba respetar esos desarrollos, acordes con el pluralismo político. Con todo, como se sabe, no todos los preceptos de la Constitución poseen el mismo valor jurídico, ni permiten la misma densidad de control por parte del Tribunal Constitucional.

Así, salvo en Francia, el Preámbulo no se emplea como parámetro de control específico. En los últimos años han ido ganando operatividad, si bien ésta es aún escasa, los principios constitucionales estructurales o básicos para resolver casos concretos. La excepción viene marcada por la extendida utilización del principio de igualdad, que se conecta siempre con alguna relación jurídica concreta. Por eso, el "test" o prueba para su aplicación es casi igual en todos los países europeos, dado que se fundamenta en la razonabilidad y en la proporcionalidad, variando las técnicas concretas según la estructura del precepto, lo que da lugar a soluciones diversas. Otros principios, como la división de poderes o la protección de las minorías han conducido, en países como Francia, a una ampliación de la reserva de ley

\footnotetext{
${ }^{10}$ E. Aja y M. González Beilfuss, “Conclusiones generales”, en E. Aja (coord.), “Las tensiones...”, op. cit., págs. 265-266.
}

DiReITOS Fundamentais $\mathcal{E}$ JustiÇA N' 11 - ABR./Jun. 2010 
en protección del pluralismo y de la participación de las minorías parlamentarias en la elaboración de la ley. A su vez, los Tribunales Constitucionales protegen la distribución del poder entre la Federación y los territorios (Estados, Regiones o Comunidades Autónomas), dilucidando la titularidad de las competencias entre las dos instancias políticas.

Pero, sin duda, la parte de la Constitución protagonista por excelencia del control de constitucionalidad en Europa es la formada por los derechos fundamentales de la persona. Los derechos fundamentales son parte decisiva del parámetro de constitucionalidad, tanto por la vía del recurso directo como por la vía incidental, destacando ésta en aquellos países como Italia donde no existe aquél. En todo caso, la dimensión objetiva de los derechos fundamentales trasciende la clásica concepción del Tribunal Constitucional como legislador negativo. Por lo demás, la intensidad del control de constitucionalidad varía enormemente según la materia sobre la que recae: derechos de autonomía y libertad, derechos políticos, organización de las instituciones y derechos sociales y políticas públicas. Los mismos forman una escala que va desde el mayor rigor del control de constitucionalidad, hasta el menor, que comporta conferirle al legislador una mayor libertad de opciones.

También es necesario subrayar la extensión sufrida en el canon de constitucionalidad por la inclusión en el mismo de otras normas en los distintos países, a través de vías diversas. Así, hay que referirse, destacadamente, a la inclusión de normas interpuestas, que son las llamadas por la propia Constitución para condicionar la aprobación de nuevas leyes. Importantes son aquí los reglamentos parlamentarios, que regulan el procedimiento legislativo. También, a veces, los tratados internacionales, según en qué países, sobre todo en lo que se refiere a la interpretación de los derechos fundamentales (art. 10.2 CE). Y en cuanto al Derecho europeo hay que decir, sin embargo, que los Tribunales Constitucionales se niegan a valorar las contradicciones entre dicho derecho y las leyes nacionales, dejando ese cometido al Tribunal de Justicia de la Unión. Un supuesto especial se da en España con los Estatutos de Autonomía de las Comunidades Autónomas, que operan como normas constitucionales derivadas o de segundo grado. Y, finalmente, hay que destacar la importancia adquirida, a estos efectos, por la propia doctrina de los Tribunales Constitucionales, la cual formula constantemente auténticas normas subconstitucionales. Así, todos los tribunales ordinarios deben interpretar las leyes de acuerdo con esa doctrina en todo tipo de procesos. La misma se convierte en fuente del Derecho, en sentido amplio, particularmente en ámbitos como el derecho procesal, dadas las numerosísimas sentencias recaídas sobre el derecho a la tutela judicial efectiva, incorporándose a las nuevas leyes que se van elaborando ${ }^{11}$.

\subsubsection{El contenido de las sentencias constitucionales y sus diferentes tipos}

La proliferación de muy diversos tipos de sentencias constitucionales obedece a la insuficiencia explicativa de la dicotomía nulidad-validez, en los pronunciamientos de los Tribunales Constitucionales. Esa dicotomía no responde, además, ya, a la

${ }^{11}$ F. Caamaño Domínguez y otros, “Jurisdicción y Procesos Constitucionales”, Madrid, McGraw-Hill, 2004, págs. 63 y ss. 
compleja realidad actual $^{12}$. Sin embargo, pocos países prevén expresamente soluciones distintas a la nulidad. Así, en la práctica, los Tribunales Constitucionales buscan la obtención de soluciones nuevas, sin atenerse a lo previsto, apartándose de la teoría del legislador negativo; si bien se insiste en la necesidad de fijar límites a esa discrecionalidad para evitar la invasión del espacio constitucionalmente reservado al legislador.

Sistematizaremos seguidamente los diversos tipos de sentencias existentes, inexplicables a la luz de la teoría del legislador negativo. Para ello se tendrán en cuenta las relaciones que se establecen entre el Tribunal Constitucional y el legislador. Destacan así, de acuerdo con la útil sistematización elaborada por E. Aja y M. G. Beilfuss, tres grandes tipos de sentencias: 1) las simples, que declaran la constitucionalidad o inconstitucionalidad de la ley); 2) las que resuelven unilateralmente la inconstitucionalidad de la ley, incorporando a la misma algún elemento normativo; 3) y las que no solucionan inmediatamente la invalidez de la ley y llaman a la colaboración bilateral con el legislador. Dentro de cada tipo existen múltiples variantes ${ }^{13}$. Así,

1) Sentencias simples, de admisión o rechazo de la inconstitucionalidad. Son las tradicionales, ya que hacen que el Tribunal Constitucional actúe como legislador negativo. Resultan, para el objeto de esta exposición, menos interesantes, aunque no debe dejar de advertirse que la declaración de nulidad parcial de un precepto puede provocar efectos aditivos en la práctica. De todos modos, salvo en Francia, si la sentencia es desestimatoria del recurso o cuestión, ello no impide un nuevo recurso o cuestión, alegando distintos motivos. Pero si la sentencia es estimatoria y declara la inconstitucionalidad de la ley el efecto general es la expulsión del ordenamiento.

2) Sentencias "unilaterales" que modifican algún elemento de la ley, resolviendo su inconstitucionalidad. Son supuestos en los que la decisión del Tribunal Constitucional da un nuevo sentido a la ley, creando una norma nueva, lo que le lleva a actuar como legislador positivo. Habitualmente se alega el principio de interpretación conforme a la Constitución, aunque también el principio de conservación de las normas, apelando a la protección de la ley o a la intención del legislador. Las variantes más frecuentes de estas sentencias son las siguientes: a) Sentencias interpretativas: establecen una interpretación concreta y diferente a lo que se deduce de la literalidad del precepto legal, recreándolo, de forma más amplia o restrictiva que como fue determinado por el legislador. Suelen ser desestimatorias formalmente, no incluyendo un pronunciamiento de inconstitucionalidad, si bien materialmente suponen la estimación del recurso o cuestión, ya que el Tribunal Constitucional no acepta la norma originaria, sino que la transforma en otra; b) Sentencias que contienen una declaración de inconstitucionalidad parcial "cuantitativa": son las que anulan sólo una palabra o frase del texto normativo impugnado, cambiando con ello la norma y el sentido del precepto. Por ejemplo, una sentencia que disponga la igualdad de los viudos y las viudas en el régimen de las pensiones, suprimiendo los requisitos adicionales dispuestos por la ley para los hombres, con lo que los equipara con las mujeres. Mediante estas sentencias se busca

12 J. Jiménez Campo, “La declaración de inconstitucionalidad de la ley” en F. Rubio Llorente y J. Jiménez Campo, "Estudios...”, op. cit., págs. 121 y ss.

${ }^{13}$ E. Aja Fernández y M. González Beilfuss, “Las tensiones...”, op. cit., págs. 274 y ss. 
evitar los vacíos en el ordenamiento provocados por una resolución meramente anulatoria del precepto impugnado; y c) Sentencias que contienen una declaración de inconstitucionalidad parcial "cualitativa": son las que, sin suprimir el precepto impugnado, excluyen una norma contenida en el mismo, en la medida en que su sentido resulta contrario a la Constitución. Se pretende así depurar de posibles sentidos inconstitucionales la norma impugnada. Así, lo que se hace es declarar el texto inconstitucional, "en la medida en que", "en cuanto que” deja de regular, o regula de forma diferenciada un supuesto. Las sentencias “integrativas” y "sustitutivas”, llamadas “aditivas” en Italia y “constructivas” en España, expresan el efecto positivo indicado, pues amplían la norma, adicionan un nuevo elemento al texto juzgado parcialmente inconstitucional, o, incluso, sustituyen un régimen jurídico por otro. El problema que estas sentencias causan es que imponen a los jueces una sola interpretación de la ley, limitando su facultad para interpretar y aplicar las leyes. Además, de esta forma, no se espera a la ley reformadora del Parlamento, sino que es el propio Tribunal Constitucional el que corrige y regula la situación por sí mismo.

3) Sentencias "bilaterales" que llaman a la colaboración del legislador para solucionar la inconstitucionalidad de la ley. Aquí el Tribunal Constitucional no anula la ley, como en las sentencias simples, ni remedia el vicio de constitucionalidad, como en las unilaterales, sino que encomienda al legislador la modificación de la norma que considera inconstitucional. Sus variantes más conocidas son: a) Las sentencias “apelativas”, así llamadas en Alemania, en las que se declara que la ley “todavía no es inconstitucional”, pero el legislador debe cambiarla. En los demás países incluyen orientaciones o admoniciones al legislador. Son sentencias que constituyen, por tanto, una amenaza al legislador, que si no modifica la norma, se expone a que, en una sentencia futura, se la declare inconstitucional; b) Sentencias que declaran la inconstitucionalidad sin nulidad (Alemania); o que posponen la entrada en vigor de los efectos de la inconstitucionalidad (Austria), Estado éste último en el que existe la posibilidad de que una sentencia que declara la inconstitucionalidad de una norma no tenga efectos inmediatos, sino que vaya acompañada de un aplazamiento de la derogación de la norma. Ese plazo, ahora de dieciocho meses, se destina a que el Parlamento pueda modificar o sustituir la normativa inconstitucional. Durante ese plazo la norma se sigue aplicando, salvo para el caso en el que se ha declarado inconstitucional. La misma no puede volver a impugnarse. Esta técnica respeta las funciones respectivas del Tribunal Constitucional y del legislador, expresando la división de poderes. Así, el Tribunal Constitucional controla, el Parlamento repara y se evitan los inconvenientes del vacío normativo. No obstante, se cuestiona seguir aplicando una ley declarada inconstitucional. Lo que sucede en Austria es que la declaración de inconstitucionalidad no genera, como en los demás países, una nulidad “ex tunc” (declarar que la norma fue inválida “ab initio"), sino la mera derogación ("ex nunc": declarar que es inválida desde el momento de la sentencia). Por su parte, en Alemania, desde 1970, se admite la práctica de declarar una ley inconstitucional, pero sin acompañarla de la nulidad correspondiente. Así, el Tribunal Constitucional puede fijar un plazo al legislador para que sustituya la norma, sin que la ley se aplique durante ese plazo, salvo excepcionalmente. 
Además, en Alemania algunas sentencias establecen un régimen jurídico provisional, en tanto el legislador no regule nuevamente la materia. En cualquier caso, el proceder que se sigue en Austria y Alemania, pese a las dudas que suscita el comportamiento de los operadores jurídicos durante el plazo dado al legislador para sustituir la norma declarada inconstitucional y a la garantía de que el legislador apruebe a tiempo la nueva ley, apuntan la vía para superar las dificultades de una Justicia Constitucional que no puede limitarse a ser legislador negativo, pero que tampoco debe convertirse, abiertamente, en un legislador positivo; c) Sentencias con mandatos y recomendaciones al legislador: Son muy frecuentes, salvo en Portugal. Contienen orientaciones, mandatos, dirigidos al legislador, señalándole las líneas que debe contener la futura ley. Son sentencias que afectan principalmente a cuestiones tributarias o económicas. Algunas contienen mandatos rigurosos que manifiestan la amenaza encubierta de que, en caso de que el legislador incumpla tales mandatos, se producirá una declaración futura de inconstitucionalidad. Habitualmente, los Parlamentos respetan esas orientaciones. La inconstitucionalidad por omisión absoluta es una variante de esta categoría, pero sólo se prevé en Portugal, donde apenas se ha aplicado. En Alemania y España se produce algo parecido en materia de derechos fundamentales, a través del recurso de amparo, cuando la ausencia de la ley prevista por la Constitución acarrea la subsistencia de un obstáculo que supone la vulneración del derecho fundamental. Pero aquí no se acude al control de constitucionalidad, sino que se protege el derecho aplicando directamente la Constitución (“extra legem”), aunque ello implique una urgente llamada al legislador para que apruebe la ley correspondiente.

\subsubsection{Los efectos de las sentencias}

Los efectos generales de las sentencias constitucionales están expresamente contemplados en las leyes reguladoras respectivas. En cualquier caso, los problemas que plantean son bastante homogéneos. Ello se debe a la común adopción del sistema europeo de control de constitucionalidad y, con él, de sus notas de concentración y de efectos "erga omnes" 14 . En lo que se refiere al efecto de cosa juzgada, hay que decir que éste se admite en su dimensión formal (irrecurribilidad y consecuente firmeza de las sentencias constitucionales). Más problemática es la dimensión material de la cosa juzgada: así, en las sentencias desestimatorias (incluyendo a las interpretativas), ese efecto de cosa juzgada, o bien se rechaza, como en Portugal; o bien se matiza ampliamente, recordando el carácter dinámico de la interpretación constitucional y la consiguiente posibilidad de instar la revisión de la doctrina de los Tribunales Constitucionales. Por otra parte, en relación al carácter vinculante de las sentencias, en Portugal y Alemania se insiste en la necesidad de modular la clásica prohibición, dirigida al legislador futuro, de reiteración de normas inconstitucionales. Se abre así paso a un modelo más dinámico de justicia constitucional, adecuado a la cambiante frontera entre constitucionalidad e inconstitucionalidad.

Un aspecto especialmente problemático de las sentencias constitucionales, materialmente estimatorias de inconstitucionalidad, es el de sus efectos temporales. Así, la nulidad "ex tunc" (retroacción de la inconstitucionalidad) ha sido categoría

${ }^{14}$ F. Caamaño Domínguez y otros, “Jurisdicción y Procesos Constitucionales”, op. cit., págs. 141 y ss. 
habitual en Alemania, España, Italia y Portugal; mientras que la derogación (efectos sólo "pro futuro" o "ex nunc") lo ha sido en Austria; si bien dichos efectos han sido relativizados en todos estos países.

Así, 1) primeramente, los efectos de la nulidad "ex tunc" son limitados, en aras de la seguridad jurídica. Una excepción habitual afecta a las normas penales favorables. 2) Por otro lado, en el caso austriaco, la inconstitucionalidad puede también tener efectos retroactivos, al menos, respecto al caso concreto que da origen a la sentencia. De todas formas, en Austria y Portugal, sus respectivos ordenamientos permiten a sus Tribunales Constitucionales modular, sin apenas límites, los efectos temporales de sus sentencias.

Una segunda matización en relación a los efectos temporales de las sentencias procede de la propia jurisprudencia de los Tribunales Constitucionales. 1) Así, en los países en los que se estipula la retroacción de la inconstitucionalidad, los Tribunales Constitucionales suelen salvaguardar las aplicaciones ya consolidadas de la norma inconstitucional. De esta forma, se limitan los efectos retroactivos, poniendo a salvo, sobre todo, los actos administrativos consolidados. 2) Por su parte, el Tribunal Constitucional austriaco ha determinado la retroactividad de algunos actos de aplicación de la norma inconstitucional distintos del que da lugar a la sentencia. Sin embargo, esta jurisprudencia ha fomentado indirectamente que en ámbitos como el tributario de produzca una avalancha de recursos administrativos y jurisdiccionales que pretenden mantener abiertos los casos para que puedan beneficiarse de una posible sentencia constitucional estimatoria. Ello ha obligado, por ejemplo, al Tribunal Constitucional alemán a dar otorgar efectos, sólo, "pro futuro" a la sentencia constitucional, manteniendo, incluso, en vigor, provisionalmente, la norma declarada inconstitucional, lo que pone de manifiesto que, a pesar de la existencia de claras categorías dogmáticas, el debate acerca de los efectos temporales de las sentencias constitucionales sigue abierto. Esta necesidad de matizar tales efectos, en función de las circunstancias del caso concreto, implica una actividad positiva y recreadora de los efectos temporales de la inconstitucionalidad que se aleja de la tradicional concepción negativa de la justicia constitucional. Ello obliga a desarrollar criterios dogmáticos que legitimen y doten de previsibilidad a los mismos, ayudando a interpretar las cláusulas generales en los países donde éstas existen.

Otra dimensión del problema afecta a los efectos hacia el futuro de las sentencias estimatorias de inconstitucionalidad. Y es que resulta, a veces, muy problemático crear un vacío normativo en el lugar de la norma inconstitucional. Esto ha sido también matizado en la normativa y en la práctica de los Tribunales Constitucionales. Así, en Austria es frecuente que el Tribunal Constitucional retrase la entrada en vigor de la sentencia hasta un total de dieciocho meses, durante los cuales la norma inconstitucional se sigue aplicando, sin que pueda volver a impugnarse. Ello expresa la creciente dificultad de soportar vacíos normativos en sociedades con sistemas jurídicos cada vez más complejos, en las que los poderes públicos están obligados a intervenir, de manera constante, en garantía y desarrollo de la dimensión objetiva de los derechos fundamentales. En este sentido, una vez más, destaca la práctica, cada vez más frecuente, seguida por el Tribunal Constitucional Federal alemán, consistente 
en declarar la inconstitucionalidad sin nulidad y ordenar expresamente la aplicación de la norma inconstitucional hasta que el legislador apruebe la correspondiente ley reparadora. Esta práctica, hasta ahora, ha sido rechazada por la jurisprudencia constitucional portuguesa e italiana.

Otro mecanismo para evitar el vacío normativo es el de la reviviscencia de las normas que en su día fueron derogadas por la norma declarada inconstitucional. Así se prevé, expresamente, en Austria y Portugal, donde cabe matizar esa reviviscencia. No obstante, la misma es infrecuente, dados los riesgos que comporta revivir una norma que puede resultar ya anacrónica y dudosamente constitucional. De todos modos, esta posibilidad existe, permitiendo a los Tribunales Constitucionales la posibilidad de configurar directamente el ordenamiento vigente, lo que no se puede explicar, tampoco, a partir de la concepción tradicional del legislador negativo.

\section{CONCLUSIONES}

1. Cabe afirmar la obsolescencia de visión clásica, aun dominante en Europa, que concibe a los Tribunales Constitucionales como meros legisladores negativos, habida cuenta de la mayor complejidad de sus funciones, en el contexto de los cambios introducidos en los sistemas constitucionales contemporáneos. De ahí la conveniencia de racionalizar sus relaciones con el legislador. Ello requiere introducir ciertos cambios, que han de afectar tanto al legislador, como al propio Tribunal Constitucional, los cuales deben recogerse en la normativa reguladora.

2. Por las razones indicadas, los Tribunales Constitucionales se ven impulsados a elaborar sentencias de contenido positivo. No obstante, esta tendencia no puede aceptarse sin establecer algunos límites claros. Así, como en Austria, puede ser operativo distinguir en las sentencias intermedias, que representan hoy el punto más conflictivo, entre la declaración de inconstitucionalidad, que compete al Tribunal Constitucional, y la reparación del vicio, que corresponde al legislador. Esta es la orientación que se observa en las sentencias llamadas bilaterales.

3. Es necesario, a su vez, avanzar en la configuración de una superior colaboración entre el Tribunal Constitucional y el legislador. La creación de instrumentos que flexibilicen las relaciones entre ambas instituciones, como la memoria anual del Tribunal Constitucional, recordando las normas pendientes de reforma, o la creación de gabinetes de enlace del Tribunal Constitucional con el Gobierno y el Parlamento, para facilitar el cumplimiento de las sentencias constitucionales; o la previsión de reuniones periódicas, u otro tipo de relaciones institucionales, pueden ayudar a encauzar el problema.

4. Lo esencial del problema reside en la existencia efectiva de sentencias que suponen la creación de normas y de la consiguiente necesidad de prever para ellas un régimen constitucional y legal diferente al tradicional. Así, debe distinguirse cuándo puede el Tribunal Constitucional resolver por sí mismo la inconstitucionalidad y cuándo no puede hacerlo, y debe recurrir al legislador. Y es que hay casos en los que la respuesta puede ser variable, siendo una opción típica del legislador, como en los problemas referidos a la aplicación del principio de igualdad; mientras que en otros, se impone una sola respuesta constitucionalmente posible, determinable por propio Tribunal Constitucional. En cualquier caso, hay que fijar límites claros a esa 
función positiva del Tribunal Constitucional, como ya se ha hecho en materia penal. Así, conviene avanzar en el camino trazado por las sentencias bilaterales, especialmente, haciendo que el Tribunal Constitucional dicte sentencias de inconstitucionalidad sin nulidad, al tiempo que se le deja una mayor libertad de decisión y se confiere mayor eficacia a la tarea del legislador.

5. Se necesita, también, que las leyes reguladoras de la jurisdicción constitucional en Europa, o, en su caso, las respectivas Constituciones, admitan la posibilidad de que los Tribunales Constitucionales se dirijan al legislador para exigirle, en plazos razonables, que apruebe las normas que remedien la inconstitucionalidad, configurando esta intervención legislativa como obligación jurídica estricta. Para ello deberían modificarse, igualmente, los reglamentos parlamentarios. Sin embargo, ello no debería impedir al Parlamento la aprobación de una ley de orientación diferente a la sugerida por el Tribunal Constitucional, ni el sometimiento de la misma al control de constitucionalidad.

6. En definitiva, se hace preciso modificar el paradigma aun dominante en Europa que insiste en la anacrónica idea de que el Tribunal Constitucional ha de comportarse como un mero legislador negativo, al tiempo que se predica la actuación separada del legislador, como si éste fuera soberano, y no existiera el Tribunal Constitucional. Sólo así se conseguirá adecuar el funcionamiento de ambas instituciones a la compleja realidad existente, mejorando notablemente el funcionamiento de nuestro modelo de democracia avanzada: la propia de los Estados sociales y democráticos de Derecho.

\section{REFERENCIAS}

CAMPO, J. Jiménez. La declaración de inconstitucionalidad de la ley, in: LLORENTE, F. Rubio e CAMPO, J. Jiménez. Estudios sobre Jurisdicción Constitucional, Madrid, McGraw-Hill, 1998.

CAPPELLETTI, Mauro. Il controllo giudiziario di costituzionalità delle leggi nel Diritto comparato, Milano, Giuffré, 1979.

DOMÍNGUEZ, F. Caamaño et al. Jurisdicción y Procesos Constitucionales, Madrid, McGraw-Hill, 2004.

ENTERRÍA, E. García. La Constitución como norma y el Tribunal Constitucional. Madrid, Civitas, 1981.

FERNÁNDEZ, E. Aja (ed.). Las tensiones entre el Tribunal Constitucional y el Legislador en la Europa actual, Barcelona, Ariel, 1998.

KELSEN, Hans. La garantie jurisdictionnelle de la Constititution (La Justice Constitutionnelle). Revue de Droit Public, Vol. XLV, 1928.

LLORENTE, F. Rubio. La Jurisdicción Constitucional como forma de creación del Derecho, in: La forma del poder, Madrid, 1993.

ROYO, J. Pérez. Tribunal Constitucional y división de poderes, Madrid, Tecnos, 1988.

VILLALÓN, P. Cruz. La formación del Sistema Europeo de Control de Constitucionalidad 1918-1939, Madrid, Centro de Estudios Constitucionales, 1987. 